\title{
O CRITÉRIO DE DETERMINAÇÃO DA NACIONALIDADE NA LEI N 5.709, DE 1971, PARA AQUISIÇÃO DE IMÓVEIS RURAIS POR PESSOAS JURÍDICAS
}

\section{THE CITIZENSHIP STANDARD OF THE LAW No 5.709/1971, FOR ACQUISITION OF COUNTRYSIDE REAL ESTATE BY SOCIETIES}

\begin{abstract}
${ }^{1}$ Victor Fróis Rodrigues
\section{RESUMO}

Este trabalho objetiva apresentar e analisar a controvérsia jurídica instaurada em torno da recepção constitucional do $\S 1^{\circ}$ do artigo $1^{\circ}$ da Lei $n^{\circ} 5.709$, de 1971 , que estabelece uma discriminação entre pessoas jurídicas nacionais. Como será demonstrado, o diploma em referência discrimina as pessoas jurídicas nacionais controladas por estrangeiros nãoresidentes no país daquelas controladas por nacionais ou estrangeiros residentes no país, para efeitos de sujeição às restrições e condições impostas para aquisição de imóveis rurais. $\mathrm{O}$ tema é palpitante, sobretudo em razão da recente alteração de entendimento da AdvocaciaGeral da União no Parecer LA 01/2010, que teve seu teor ratificado pelo Presidente da República para produção de efeitos vinculativos de toda a Administração Pública Federal. Neste contexto, o Conselho Nacional de Justiça também foi instado a se manifestar sobre a matéria para harmonizar os procedimentos no âmbito da serventias extrajudiciais. Até o momento o Supremo Tribunal Federal não foi provocado para realizar o devido controle de constitucionalidade, o que abre margem para uma nova mudança de paradigma.
\end{abstract}

Palavras-chave: Aquisição de imóveis rurais, Pessoas jurídicas estrangeiras, Recepção constitucional

\begin{abstract}
This work aims to present and analyze a legal controversy about the constitutional reception of the paragraph $1^{\circ}$, article $1^{\circ}$, of the Law $n^{\circ} 5.709 / 71$, which establishes a distinction between different kinds of national societies. As will be demonstrated, the law in reference discriminates national societies for being controlled or not non-residents foreign in the country, for the application of the restrictions on countryside real estate acquisition. The theme is interesting because of the recent understanding change made by the AdvocaciaGeral da União through the opinion $n^{\circ}$ LA 01/2010, ratified by the Republic President and causing effects throughout the federal public administration. In this context, the Conselho Nacional de Justiça also spoke about the matter to harmonize procedures within the framework of the notaries. Until now the Brazilian Supreme Court has not been called up to judge the constitutionality of the matter, opening room for a paradigm shift.
\end{abstract}

Keywords: Countryside real estate acquisition, Foreign business societies, Constitutional reception

\footnotetext{
1 Mestrando em Direito pela Faculdades Milton Campos - FMC, Minas Gerais (Brasil). E-mail: vfroisrodrigues@gmail.com
} 


\section{INTRODUÇÃO}

A propriedade recebe tratamento de destaque em nosso ordenamento jurídico, não por acaso foi elevada ao patamar de direito fundamental pela Constituição da República.

Ciente da importância econômica, política e social que traz a propriedade, o constituinte originário cuidou de prever o dever dos proprietários de conferir-lhe a devida função social.

Estipulada esta premissa, a Lei Federal n 5.709, de 1971, regulou forma e condições para aquisição de imóveis rurais por pessoas físicas estrangeiras residentes no país e jurídicas estrangeiras autorizadas a funcionar no país.

A determinação de limites, condições e forma para aquisição de propriedade rural por estrangeiros é de suma importância ao resguardo e ao atendimento da função social e do interesse público, evitando assim a entrada desregrada de capital especulativo estrangeiro que acarretaria no aumento substancial do preço da propriedade imobiliária e na manutenção do estado de improdutividade de muitas terras do país.

Não obstante, o trabalho adiante desenvolvido busca explorar os aspectos pertinentes ao critério da nacionalidade adotado pela Lei 5.709, de 1971, em especial quanto às pessoas jurídicas, sem olvidar da necessária demarcação teórica dos conceitos envoltos e relacionados.

Esse critério, como será demonstrado, suscita acalorado debate sobre sua recepção constitucional, devido a importância que contorna sua aplicação. Uma vez reputada estrangeira, a pessoa jurídica se submeterá integralmente as exigências contidas no diploma referido, o que acarreta repercussões nas esferas jurídica, econômica e até mesmo política.

Para evitar maiores digressões sobre a matéria, o trabalho se desenvolverá em torno dos análise crítica dos diversos pareceres expedidos pela órgão da Advocacia-Geral da União sobre critério de nacionalidade estabelecido na Lei n ${ }^{\circ}$ 5.709, de 1971.

\section{O REGIME JURÍDICO DO IMÓVEL RURAL}

A doutrina segmentou o tratamento da propriedade imobiliária em urbana e rural, em que pese detentoras dos mesmos atributos (usar, fruir, dispor e reaver), a Constituição as distingue para efeitos de determinação da forma de cumprimento de suas respectivas funções sociais.

O constituinte consagrou uma nova roupagem ao direito de propriedade, destacando as obrigações que decorrem da titulação destes direitos reais, conforme lição de Carlos Alberto Dabus Maluf: 
Ao antigo absolutismo do direito, consubstanciado no famoso ius utendi et abutendi, contrapõe-se, hoje, a socialização progressiva da propriedade orientando-se pelo critério da utilidade social para maior e mais ampla proteção aos interesses e às necessidades comuns (MALUF, 2011, p. 73-74).

Com efeito, os artigos 182 da Constituição e 39 do Estatuto da Cidade preveem que a função social da propriedade urbana é cumprida quando atende às exigências fundamentais de ordenação na cidade expressas no plano diretor do município, assegurando o atendimento das necessidades dos cidadãos quanto à qualidade de vida, à justiça social e ao desenvolvimento das atividades econômicas.

Por sua vez, o artigo 186 da Constituição prevê que a função social da propriedade rural é cumprida quando atende, simultaneamente, segundo critérios e graus de exigência estabelecidos pela legislação própria, aos seguintes requisitos: aproveitamento racional e adequado, utilização adequada dos recursos naturais disponíveis e preservação do meio ambiente, observância das disposições que regulam as relações de trabalho e a exploração que favoreça o bem-estar dos proprietários e dos trabalhadores.

Cumpre anotar a pertinente observação feita Flávio Tartuce (p.859):

O CC/02 foi além de tratar da função social, pois ainda consagra a função socioambiental da propriedade. Há tanto uma preocupação com o ambiente natural (fauna, flora, equilíbrio ecológico, belezas naturais, ar e água), como com o ambiente cultural (patrimônio cultural e artístico). Exemplificando, o proprietário de uma fazenda, no exercício do domínio, deve ter cuidado para não queimar uma floresta e também para não destruir um sítio arqueológico (TARTUCE, 2013, p. 859)

Esclarecida a diferença de tratamento despendido à propriedade urbana e rural, passamos a análise dos critérios utilizados pela doutrina para determinar em que área o imóvel está localizado, urbana ou rural.

São dois os critérios apresentados pela doutrina para distinguir os prédios rurais (rústicos) dos urbanos, o primeiro deles é o da localização e o segundo é o da destinação econômica.

Pelo critério da localização, reputa-se rural o prédio localizado fora dos perímetros urbanos dos município, o que deverá ser apurado através da análise do respectivo plano diretor. 
Como a edição de lei que estabeleça o plano diretor somente é obrigatória nas hipóteses em que o município tenha mais de vinte e cinco mil habitantes, ou que seja integrante de região metropolitana, ou quando o Poder Público municipal pretenda utilizar dos instrumentos de parcelamento/edificação compulsórios e do imposto sobre propriedade territorial e predial urbana progressivo no tempo, devem ser observados, igualmente, os critérios subsidiários de localização descritos pelo artigo 32 do Código Tributário Nacional:

Art. 32. O imposto, de competência dos Municípios, sobre a propriedade predial e territorial urbana tem como fato gerador a propriedade, o domínio útil ou a posse de bem imóvel por natureza ou por acessão física, como definidos na lei civil, localizado na zona urbana do município.

$\S 1^{\circ}$ - Para efeitos deste imposto, entende-se como zona urbana a definida em lei municipal; observado o requisito mínimo da existência de melhoramentos indicados em pelo menos dois dos incisos seguintes, construídos ou mantidos pelo Poder Público:

I - meio-fio ou calçamento, como canalização de águas pluviais;

II - abastecimento de água;

III -sistema de esgotos sanitários;

IV - rede de iluminação pública, com ou sem posteamento para distribuição domiciliar;

V - escola primária ou posto de saúde a uma distância máxima de três quilômetros do imóvel considerado.

Contudo, a alteração que o Decreto-lei n ${ }^{\circ}$ 57/1966 promoveu na sistemática de lançamento do imposto sobre a propriedade territorial rural (ITR), fazendo prever que o disposto no artigo 32 do Código Tributário Nacional não abrange o imóvel que, comprovadamente, seja utilizado em exploração agrícola, pecuária ou extrativista, fez prevalecer o critério da destinação econômica.

A respeito do critério da destinação econômica Eduardo Pacheco Ribeiro de Souza elucida que:

A doutrina apresenta dois critérios para distinção entre os prédios rurais e urbanos, o da localização e o da destinação econômica. Pelo primeiro critério, será rural o imóvel que estiver fora dos perímetros urbanos dos municípios; pelo segundo, será o imóvel destinado à exploração agrícola, pecuária, extrativa ou agroindustrial, qualquer que seja a sua localização. Prevalece hodiernamente o critério da destinação, previsto no art. $4^{\circ}, \mathrm{I}$, do Estatuto da Terra (Lei $\mathrm{n}^{\circ}$ 4.504/1964): "para os efeitos desta Lei, 
definem-se: I - 'Imóvel Rural', o prédio rústico, de área contínua qualquer que seja a sua localização, que se destina à exploração extrativa agrícola, pecuária ou agroindustrial, quer através de planos públicos de valorização, quer através de iniciativa privada" (SOUZA, 2014, p. 9).

Vale ressaltar que o Estatuto da Terra considera como sendo um único imóvel rural duas ou mais áreas confinantes pertencentes ao mesmo proprietário ou não, desde que mantida a unidade econômica entre elas, entendimento respaldado pelo Instituto Nacional de Colonização e Reforma Agrária - INCRA - que adota esta definição para elaboração de seu cadastro de imóveis rurais e emissão dos respectivos certificados (Certificado de Cadastro do Imóvel Rural - CCIR).

Registre-se, todavia, que para os Cartórios de Registro de Imóveis, responsáveis por garantir a publicidade, autenticidade, segurança jurídica e eficácia dos atos e negócios jurídicos envolvendo direitos reais imobiliários, considera-se imóvel rural a área descrita na matrícula como tal, independentemente desta constituir ou não uma unidade econômica com outra qualquer.

A respeito do tema, Ridalvo Machado de Arruda expõe que:

Diferentemente do sistema de cadastro do INCRA, no Registro de Imóveis a área descrita na matrícula representará uma unidade imobiliária. No cadastro do INCRA, o imóvel rural poderá ser constituído por várias matrículas, por parcelas de matrículas (nas frações ideais em que a posse é localizada) e até mesmo por áreas de posse. No Registro de Imóveis, não é assim. Cada matrícula representa uma unidade imobiliária, mas nada impede que o proprietário requeira ao oficial de registro a unificação das áreas descritas em suas matrículas, desde que a fusão dessa matrículas (ou transcrições) seja juridicamente possível, providência esta que resultará em um nova matrícula com a descrição do perímetro total dessas áreas, formando-se, assim, uma nova unidade imobiliária (ARRUDA, 2011, p. 1).

\section{OS CRITÉRIOS DE DETERMINAÇÃO DA NACIONALIDADE DAS PESSOAS FÍSICAS E JURÍDICAS}

Nacionalidade, em sua acepção jurídica, é a qualidade de um indivíduo como membro de um Estado (CARVALHO, 2008, p. 797).

A determinação da nacionalidade da pessoa física pode se dar por dois critérios, o do ius soli ou do ius sanguines. O primeiro considera a nacionalidade com base no local de 
nascimento da pessoa, o segundo, considera a nacionalidade dos ascendentes para definir a dos descendentes.

Nossa Constituição adota como regra o critério do ius soli e, excepcionalmente, o critério do ius sanguines:
Art. 12. São brasileiros:
I - natos:
a) os nascidos na República Federativa do Brasil, ainda que de país estrangeiros, desde que estes não estejam a serviço de seu país; b) os nascidos no estrangeiro, de pai brasileiro ou mãe brasileiro, desde que qualquer deles esteja a serviço da República Federativa do Brasil;
c) os nascidos no estrangeiro de pai brasileiro ou de mãe brasileira, desde que sejam registrados em repartição brasileira competente ou venham a residir na República Federativa do Brasil e optem, em qualquer tempo, depois de atingida a maioridade, pela nacionalidade brasileira;

Insta destacar, a respeito da alínea "c", do inciso I, do Artigo 12 da Constituição da República, que a fixação de residência no Brasil e a opção, tal como previstas, não geram nacionalidade, pois esta já existe antes daquelas condições que apenas suspendem o exercício da condição de brasileiro enquanto não ocorridas (GUIMARÃES, 2002, p. 27).

A nacionalidade também pode ser adquirida de forma derivada, o que se denomina de procedimento de naturalização, tema a ser melhor explorado em outra oportunidade.

Desde a edição da Emenda Constitucional n 6, de 1995, que revogou expressamente o artigo 171 da Constituição, não existe disposição constitucional dirigida ao estabelecimento de critérios para distinguir a pessoa jurídica privada nacional, de uma internacional.

O dispositivo revogado descriminava as empresas com sede e administração no país, além de constituídas conforme o ordenamento pátrio, reputando nacionais apenas aquelas cujo controle efetivo (maioria do capital votante) estivesse, em caráter permanente, sob a titularidade direta ou indireta de pessoas físicas domiciliadas e residentes no Brasil ou entidades de direito público interno.

Até 1995 as empresas com sede e administração no Brasil e constituídas conforme a legislação nacional, mas cujo controle efetivo estivesse, de forma permanente, nas mãos de pessoas físicas residentes e domiciliadas no exterior, poderiam ser preteridas na concessão de benefícios e vantagens pelo governo. 
Com a edição da Emenda Constitucional nº 6, de 1995, foi revogada a discriminação existente entre empresas nacionais, sendo apenas permitido o tratamento favorecido para as empresas de pequeno porte constituídas em acordo com a legislação brasileira, em desfavor de todas as demais (artigo 170, IX, CR).

A disciplina da matéria foi subjugada à legislação ordinária, mais especificamente ao Código Civil, que previu ser nacional a sociedade organizada em conformidade com a lei brasileira e que tenha no país sua sede de administração (artigo 1.126, Código Civil).

Mais adiante, no mesmo diploma o legislador consignou que a sociedade estrangeira, qualquer que seja o seu objeto, não pode, sem autorização do Poder Executivo, funcionar no país, ainda que por estabelecimentos subordinados, podendo, todavia, ressalvados os casos expressos em lei, ser acionista de sociedade anônima brasileira (artigo 1.134, Código Civil).

Presente e justificado o interesse nacional caberá ao Poder Executivo Federal estabelecer outras condições para o funcionamento da sociedade antes de conceder a respectiva autorização, como elucida Marcelo Fortes Barbosa Filho:

\footnotetext{
Ao ser examinado o pedido de concessão para funcionamento de sociedade estrangeira, o Ministério do Desenvolvimento, Indústria e Comércio Exterior pode estabelecer condições especiais para a atuação de dada requerente no Brasil, sempre em concordância com o interesse público. Há ampla discricionariedade na fixação de tais condições, que podem variar da concreta fixação de um capital mínimo até o estabelecimento de limites de atuação geográfica ou a determinado empreendimento individualizado. Tudo dependerá da realização de um exame pormenorizado e do posterior e cuidadoso enquadramento do empreendimento pretendido pela sociedade estrangeira (BARBOSA FILHO, 2010, p. 1095).
}

Como se observa, presente o fundamento do interesse público ou nacional poderá o Poder Executivo Federal, através do Ministério do Desenvolvimento, Indústria e Comércio Exterior expedir ato administrativo contendo as condições para instalação e funcionamento de sociedade civil ou empresária no país.

Não obstante, nada impede que o legislador elabore legislação própria para estabelecer condições gerais de instalação e funcionamento das pessoas jurídicas estrangeiras no país.

Assim procedeu o Congresso Federal ao elaborar a Lei 5.709, de 1971, que regula a aquisição de imóvel rural por estrangeiro residente no país ou pessoa jurídica estrangeira autorizada a funcionar no Brasil. 
Neste caso, precisamente, o legislador exerceu sua atribuição em atendimento ao comando constitucional que dispõe:

Art. 190. A lei regulará e limitará a aquisição ou arrendamento de propriedade rural por pessoa física ou jurídica estrangeira e estabelecerá os casos que dependerão de autorização do Congresso Nacional.

Já no capítulo destinado à regulação da comunicação social, encontramos outro dispositivo que estabelece restrições à pessoa jurídica estrangeira:

Art. 222. A propriedade de empresa jornalística e de radiodifusão sonora e de sons e imagens é privativa de brasileiros natos ou naturalizados há mais de 10 anos, ou de pessoas jurídicas constituídas sob as leis brasileiras e que tenham sede no país.

A despeito da existência de outros dispositivos constitucionais e legais que estabeleçam restrições ou condições à instalação e funcionamento de pessoas jurídicas no território brasileiro, manteremos aderência ao objeto de estudo.

\section{A AQUISIÇÃO DE IMÓVEIS RURAIS POR PESSOAS FÍSICAS ESTRANGEIRAS}

Conforme anotação anterior, a Lei $\mathrm{n}^{\circ}$ 5.709, de 1971, em conjunto com seu Decreto Regulamentador $\mathrm{n}^{\circ} 74.965$, de 1974 , foram responsáveis por estabelecer as diretrizes para aquisição de imóveis rurais por pessoas físicas e jurídicas estrangeiras no país.

A história da aquisição de imóveis rurais por estrangeiros no país remonta aos idos do Brasil Imperial, nas palavras de Vicente Cavalcanti Cysneiros:

Quanto às restrições à aquisição de terras por estrangeiros no Brasil, remontam ao Império e, na fase republicana, aos vários textos constitucionais que inseriram dispositivos nucleares sobre a matéria.

O Ato Complementar $\mathrm{n}^{\mathrm{o}} 45$, de 30 de janeiro de 1969 , no art. $1^{\circ}$, dispunha que "a aquisição de propriedade rural no território nacional somente poderá ser feita por brasileiro residente no país".

O Ato Complementar $n^{\circ} 45$ foi regulamentado pelo Decreto-Lei $n^{\circ} 494$, de 10 de março de 1969, revogado pela Lei $n^{\circ} 5.709 / 1971$, atualmente em vigor e regulamentada pelo Decreto ${ }^{\circ} 74.965 / 1974$ (CYSNEIROS, 1985, p. 22). 
Nos termos do diploma legal em comento, a pessoa física estrangeira que deseja adquirir imóvel rural deve comprovar sua residência no país (declaração firmada de próprio punho), sendo livre a aquisição que não ultrapasse o montante equivalente a três módulos de exploração indefinida.

O módulo de exploração indefinida (MEI) é unidade de medida expressa em hectares, sua dimensão varia entre cinco e cem hectares a depender da zona em que se enquadra o município, conforme enquadramento realizado pelo INCRA.

Para aquisição de imóveis rurais com área entre três e cinquenta módulos de exploração indefinida, em área continua ou descontinua, a pessoa física dependerá de autorização expedida pelo INCRA para lavratura e registro da escritura respectiva.

Impõe-se, cumulativamente, o dever de apresentar um projeto de exploração para áreas que superem os vinte módulos de exploração, ademais, torna-se indispensável o assentimento prévio do Conselho de Defesa Nacional quando o imóvel estiver localizado em faixa de fronteira.

A pessoa física brasileira casada com estrangeiro por regime de bens que estabeleça a comunicação dos bens adquiridos onerosamente na constância do vínculo conjugal também estará sujeita às restrições impostas pela Lei no 5.709, de 1971.

Vale destacar a situação do português equiparado, detalhada por Josué Carvalho, Júnior Fideles e Marcela Maciel:

Em função do Tratado de Amizade, Cooperação e Consulta entre a República Federativa do Brasil e a República Portuguesa, promulgado pelo Decreto $\mathrm{n}^{\mathrm{o}}$ 3.927/2001, que instituiu o Estatuto da Igualdade entre os brasileiros e portugueses equiparados gozam dos mesmos direitos assegurados aos brasileiros, não se sujeitando, por esta razão, às restrições impostas aos demais estrangeiros.

Contudo, alerta-se para o fato da equiparação não ser automática. No caso dos portugueses, segundo o art. 15 do Decreto $n^{\circ} 3.927 / 2001$, o Estatuto da Igualdade será atribuído por ato do Ministério da Justiça, mediante requerimento do português interessado e comprovação de sua capacidade civil e residência habitual no Brasil (CARVALHO; FIDELES; MACIEL, 2015, p. 167).

Portanto, somente os portugueses que obtiverem o devido aval do Ministério da Justiça estarão formalmente equiparados aos brasileiros e, por reflexo, dispensados de observar o disposto na Lei no 5.709 , de 1971. 
Excepcionalmente, por previsão do artigo $6^{\circ}$ do Decreto Regulamentador $n^{\circ} 74.965$, de 1974, admite-se que o estrangeiro ainda residente em seu país de origem, celebre contrato de compromisso de venda e compra de imóvel rural, com a condição de que imigre para o Brasil no prazo de três meses contados da assinatura do instrumento, sob pena de ineficácia do compromisso.

Enfim, a lei isenta da sujeição de suas condições e restrições as aquisições por estrangeiros de imóvel rural derivadas de sucessão mortis causa legítima, salvo em caso de áreas indispensáveis à segurança nacional.

\section{A AQUISIÇÃO DE IMÓVEIS RURAIS POR PESSOAS JURÍDICAS ESTRANGEIRAS}

As pessoas jurídicas estrangeiras, primeiramente, deverão comprovar a regularidade de sua instalação e funcionamento no país, com a devida autorização concedida pelo Poder Executivo Federal.

O artigo $5^{\circ}$ da Lei 5.709, de 1971, condiciona a aquisição de imóveis rurais por pessoas jurídicas estrangeiras à implantação de projetos agrícolas, pecuários, industriais ou de colonização (vinculados aos seus objetivos sociais). Dessa forma, é indispensável que se demonstre a aprovação do respectivo projeto pelo Ministério da Agricultura ou da Indústria e do Comércio, no caso de projetos de caráter industrial.

Somente poderão adquirir área que não ultrapasse cem módulos indefinidos de exploração, exceto na hipótese em que obterem autorização específica do Congresso Nacional para aquisições superiores ao limite legal.

Ademais, como também se impõe às pessoas físicas, será necessária prévia autorização do INCRA e, no caso da área estar localizada em faixa de fronteira, o assentimento do Conselho de Defesa Nacional para lavratura e registro da escritura de venda e compra.

A soma das áreas rurais pertencentes a pessoas estrangeiras, físicas ou jurídicas, não poderá ultrapassar um quarto (25\%) da superfície do Município onde se situem e, as pessoas da mesma nacionalidade não poderão ser proprietárias de mais de $10 \%$ da área rural total do Município.

O controle das aquisições de imóveis rurais por estrangeiros é realizado pelo Cartório de Registro de Imóveis da localidade, através de livro auxiliar. O Oficial tem o dever de remeter 
trimestralmente à Corregedoria de Justiça dos Estados a que estiverem subordinados e ao Ministério da Agricultura, a relação das aquisições realizadas no período.

A transferência de imóveis rurais adquiridos por pessoas estrangeiras materializar-seá, obrigatoriamente, por escritura pública lavrada em notas por tabelião, não se aplicando a dispensa da forma pública prevista no artigo 108 do Código Civil para imóveis com valor fiscal equivalente a até trinta salários mínimos.

Por fim, quando a área adquirida se destinar à realização de loteamentos rurais por empresas de colonização, a aquisição e ocupação de, no mínimo, trinta por cento da área total serão feitas, obrigatoriamente, por brasileiros.

\section{A CONTROVÉRSIA DO CRITÉRIO DE NACIONALIDADE PREVISTO NA LEI No 5.709, DE 1971}

A controvérsia que traça a matéria tem lastro no critério de nacionalidade instituído pela Lei 5.709, de 1971, que estabelece uma distinção entre as empresas constituídas conforme a ordenação nacional, com sede e administração no país.

Nos termos do $\S 1^{\circ}$ do artigo $1^{\circ}$ da diploma legal em comento:

\footnotetext{
Art. $1^{\circ}$ - $\mathrm{O}$ estrangeiro residente no País e a pessoa jurídica estrangeira autorizada a funcionar no país só poderão adquirir imóvel rural na forma prevista nesta Lei.

$\S 1^{\circ}$ - Fica, todavia, sujeita ao regime estabelecido por esta Lei a pessoa jurídica brasileira da qual participem, a qualquer título, pessoas estrangeiras físicas ou jurídicas que tenham a maioria do seu capital social e residam ou tenham sede no exterior.
}

A doutrina diverge sobre a recepção constitucional do parágrafo acima transcrito, sob o argumento de estabelecer uma discriminação indevida e sem respaldo em nossa Carta Magna, sobretudo após a edição da Emenda Constitucional nº 6, de 1995.

Vale pontuar mais uma vez, o artigo 171 da Constituição, em vigor até 1995, permitia que as empresas eminentemente nacionais, sob controle efetivo (maioria do capital votante) de pessoas físicas domiciliadas no exterior, poderiam ser preteridas em relação àquelas sob o controle efetivo de pessoas físicas residentes no país, na concessão de benefícios e vantagens pelo Poder Público.

Quer dizer, mesmo que duas pessoas jurídicas tenham sido constituídas em conformidade com a legislação própria, estabeleçam sua sede e administração no país, poderiam sujeitar-se a um discrímen legal: 
Art. 171. São consideradas:

I - empresa brasileira a constituída sob as leis brasileiras e que tenha sua sede e administração no País;

II - empresa brasileira de capital nacional aquela cujo controle efetivo esteja em caráter permanente sob a titularidade direta ou indireta de pessoa físicas domiciliadas e residentes no País ou de entidades de direito público interno, entendendo-se por controle efetivo da empresa a titularidade da maioria de seu capital votante e o exercício de fato e de direito, do poder decisório para gerir suas atividades.

$\S 1^{\circ}$ - A lei poderá, em relação à empresa brasileira de capital nacional:

I - conceder proteção e benefícios especiais temporários para desenvolver atividades consideradas estratégicas para a defesa nacional ou imprescindíveis ao desenvolvimento do País;

II - estabelecer, sempre que considerar um setor imprescindível ao desenvolvimento tecnológico nacional, entre outras condições e requisitos:

a) a exigência de que o controle de que o controle referido no inciso II do "caput" se estenda à atividades tecnológicas da empresa, assim entendido o exercício, de fato e de direito, do poder decisório para desenvolver ou absorver tecnologia;

b) percentuais de participação, no capital, de pessoas físicas domiciliadas e residentes no País ou entidades de direito público interno.

$\S 2^{\circ}$ - Na aquisição de bens e serviços, o Poder Público dará tratamento preferencial, nos termos da lei, à empresa brasileira de capital nacional.

À época, o entendimento doutrinário e jurisprudencial que prevalecia sustentava a recepção do parágrafo primeiro do artigo $1^{\circ}$ da Lei 5.709 de 1971 , chancelando o tratamento diferenciado para empresas brasileiras com capital social majoritário pertencente a estrangeiros, desde que com fundamento no desenvolvimento de atividades consideradas estratégicas para a defesa nacional ou imprescindível ao desenvolvimento tecnológico do país ( $\$ 1^{\circ}$, Artigo 171, $\mathrm{CR} / 88)$.

Equiparar as empresas nacionais controladas por estrangeiros às empresas efetivamente estrangeiras tem largas repercussões, que extrapolam o debate acadêmico jurídico.

São diversas as restrições e condições a serem preenchidas pelos estrangeiros para aquisição de um imóvel rural, o que pode ser determinante na análise de viabilidade de uma empresa ou empreendimento, como expõe Fábio Nusdeo:

Num regime de mercado, o que irá determinar a decisão da empresa por uma ou outra maneira de produzir será o preço dos fatores que, no fundo representam o seu custo. Não deve ser esquecido que ela busca, a 
maximização da diferença residual entre preço e custo, a sua remuneração específica, ou seja, o lucro.

Devem ser considerados os seguintes custos: custo direto ou variável, custo indireto ou fixo, custo médio, custo marginal, custo social e custo de transação (NUSDEO, 2008, p. 255).

Assim, em 1994 o Ministro de Estado da Agricultura, do Abastecimento e da Reforma Agrária solicitou ao Presidente da República a audiência da Advocacia-Geral da União sobre a questão.

A solicitação foi acolhida diante da premente necessidade de estabelecer um parâmetro interpretativo da legislação e, em atenção a ela a Advocacia Geral da União emitiu o Parecer AGU-GQ-22 de 1994, que foi posteriormente submetido à apreciação do Presidente da República e por este aprovado, sem, contudo, ter sido levado à devida publicação, o que nos termos do $\S 2^{\circ}$ do artigo 40 da Lei Complementar nº 73, de 1993 (Lei Orgânica da Advocacia Geral da União), somente vincula as repartições interessadas:

Art. 40 Os pareceres do Advogado-Geral da União são por este submetidos à aprovação do Presidente da República;

$\S 2^{\circ}$ - O parecer aprovado, mas não publicado, obriga apenas as repartições interessadas, a partir do momento em que dele tenham ciência.

Em síntese, o referido parecer concluiu pela recepção da Lei no 5.709 de 1971, ressalvado o $\S 1^{\circ}$ do artigo $1^{\circ}$, sob o fundamento de incompatibilidade material com a Constituição, mais especificamente, por contrariar o disposto no artigo 171, I, que de acordo com a interpretação conferida pelo parecer, não admitia essa espécie de restrição à empresa brasileira.

De acordo com o eminente parecerista, somente as restrições expressamente consignadas no texto constitucional - referentes à composição acionária de empresas brasileiras, com vistas à preservação da soberania, do interesse nacional e de setores estratégicos para o país - poderiam ser admitidas, como era o caso das comunicações (art. $222, \S^{\circ}$ ), da saúde (art. 199, $\S 3^{\circ}$ ), da pesquisa e lavra de recursos minerais e aproveitamento de potencial hidráulicos (art. 176, $\left.\S 1^{\circ}\right)$.

Em prol deste entendimento também pesava a circunstância de o artigo 190 da Constituição da República dispor sobre a possibilidade de limitação da aquisição de propriedade 
rural por estrangeiros, e não por empresas brasileiras equiparadas à estrangeiras, como pretendia o dispositivo da Lei ${ }^{\circ} 5.709$ de 1971.

Tendo em vista a superveniente revogação do artigo 171 pela Emenda Constitucional $\mathrm{n}^{\circ}$ 6, de 1995, o Advogado-Geral da União foi instado a reexaminar a matéria, no sentido de verificar se a revogação provocaria alterações na conclusão alinhavada no Parecer AGU-GQ22 .

No ano de 1998 a matéria foi apreciada através do Parecer GQ-181 de lavra do mesmo Advogado-Geral da União, desta vez, além de ratificado pelo Presidente da República, foi devidamente publicado, o que de acordo com o previsto no $\S 1^{\circ}$ do artigo 40 da Lei Complementar $n^{\circ} 73$, de 1993, confere caráter normativo ao ato e vincula a todos os órgãos e entidades da Administração Pública Federal:

Art. 40. Os pareceres do Advogado-Geral da União são por este submetidos à aprovação do Presidente da República.

$\S 1^{\circ}$ - O parecer aprovado e publicado juntamente com o despacho presidencial vincula a Administração Federal, cujos órgãos e entidades ficam obrigados a lhe dar fiel cumprimento.

Em seu teor, o parecer concluiu pela impossibilidade da Emenda Constitucional $\mathrm{n}^{\mathbf{o}}$ 6/1995 ter produzido efeito repristinatório do $\S 1^{\circ}$ do artigo $1^{\circ}$ da Lei 5.709 de 1971 , através da revogação expressa do artigo 171 da Constituição da República. O fundamento para tal conclusão está expresso no $\S 3^{\circ}$ do artigo $2^{\circ}$ da LINDB (Lei de Introdução ao Direito Brasileiro), que veda taxativamente a possibilidade jurídica da norma revogada ser restaurada pelo fato de sua lei revogadora ter perdido a vigência, a não ser que haja disposição expressa neste sentido.

Persistiu, portanto, o entendimento adotado previamente à edição da Emenda Constitucional $n^{\circ} 6 / 1995$, livrando quaisquer empresas com sede no país e constituídas de acordo com a legislação pátria, de sujeitar-se às limitações impostas para aquisição de imóvel rural por empresas estrangeiras:

Não parece, realmente, admissível que a simples revogação do art. 171 da Constituição possa ser interpretada como impedimento para que o legislador ordinário, presentes razões ligadas à soberania, à independência e ao interesse nacional, estabeleça, em determinados casos, limitações à aplicação do capital estrangeiro no País. O engessamento, antes criado pela Constituição, ao definir empresa brasileira e empresa brasileira de capital nacional, era, de fato, 
inconveniente. Assim, a desconstitucionalização da matéria atende aos interesses nacionais. Mas esse entendimento encontra-se fundamentado, justamente, na possibilidade de atuação do legislador ordinário, o que, de resto, é prática reconhecida nos países civilizados (Parecer AGU nº GQ-181, 1998).

Ocorre que os efeitos provenientes deste parecer não foram devidamente mensurados pela Advocacia Geral da União ao elaborá-lo e pelo Chefe do Executivo ao ratificá-lo.

A ausência de qualquer controle da aquisição de imóveis rurais por empresas controladas por pessoas estrangeiras, físicas ou jurídicas, ocasionou uma grande demanda por glebas, sobretudo por ter coincidido com um período de largo crescimento e abertura econômica, marcado pelas diversas reformas da administração pública e pela privatização de inúmeras empresas e serviços públicos.

As repercussões tomaram proporções macroeconômicas a partir do início do anos 2000, quando o país recebeu o título de grau de investimento e passou a ser considerado pelas grandes agências de avaliação uma economia de baixo risco de inadimplência. Com efeito, o país recebeu grandes somas de capital de investimento estrangeiro em curto período de tempo.

Este contexto despertou a atenção das autoridades, que logo atentaram à necessidade de promover mecanismos de controlar a especulação imobiliária, o avanço do cultivo em áreas de proteção ambiental e em unidades de conservação, a produção de etanol e biodiesel e a política fundiária, além da fiscalização de áreas em faixa de fronteira, reputadas imprescindíveis para a segurança nacional.

Foi a partir desta análise que a Advocacia Geral da União entendeu por necessário rever seu posicionamento quanto à recepção do $\S 1^{\circ}$ do artigo $1^{\circ}$ da Lei 5.709 , de 1971.

Em 2010 foi elaborado e publicado o Parecer LA-01/2010 pela Advocacia Geral da União, o qual também recebeu a devida chancela da Presidente da República, gerando efeitos vinculantes perante todos os órgãos da Administração Pública Federal.

A conclusão do novo parecer surpreendeu ao apontar que $\S 1^{\circ}$ do $\operatorname{artigo} 1^{\circ}$ da Lei $n^{\circ}$ 5.709, de 1971, havia sido recepcionado pela Constituição da República, seja em sua redação originária, seja após a promulgação da Emenda nº 6/1995.

Consoante tal entendimento, a pessoa jurídica constituída conforme a legislação brasileira, que mantenha sede e administração no país, mas que esteja sob o controle acionário de pessoa física estrangeira que resida no exterior, sujeita-se às restrições e condições para aquisição de imóveis rurais como estrangeiros. 
Curioso notar, conforme expõe o Advogado-Geral da União nas razões do referido parecer, que a principal motivação para mudança de entendimento não tem origem ou natureza jurídica, mas sim econômica e estratégica:

(...)6. Segundo os dados do Instituto Nacional de Colonização e Reforma Agrária - INCRA, desde 1994, data da primeira manifestação da Advocacia-Geral da União sobre o tema (Parecer GQ-22), ratificada em 1998 (Parecer GQ-181), conforme demonstrar-se-á a seguir, o Estado brasileiro perderá as condições objetivas de proceder a controle efetivo sobre a aquisição e o arrendamento de terras realizadas por empresas brasileiras cujo controle acionário e controle de gestão estivessem nas mãos de estrangeiros não-residentes no território nacional.

7. Tal situação revestia-se, então, em junho de 2007, e reveste-se ainda, de caráter estratégico, pois, a ausência de controle dessas aquisições gera, entre outros, os seguintes efeitos:

a) expansão da fronteira agrícola com o avanço do cultivo em áreas de proteção ambiental e em unidades de conservação;

b) valorização desarrazoada do preço da terra e incidência da especulação imobiliária gerando aumento do custo do processo de desapropriação voltada para a reforma agrária, bem como a redução do estoque de terras disponíveis para esse fim;

c) crescimento da venda ilegal de terras públicas;

d) utilização de recursos oriundos da lavagem de dinheiro, do tráfico de drogas e da prostituição na aquisição dessas terras;

e) aumento da grilagem de terras;

f) proliferação de "laranjas na aquisição dessas terras;

g) incremento dos números referentes à biopirataria na Região Amazônica;

H) ampliação, sem a devida regulação, da produção de etanol e biodiesel;

i) aquisição de terras em faixa de fronteira pondo em risco a segurança nacional.

8. Passados quatorze anos, o novo contexto econômico mundial, rapidamente descrito anteriormente, impunha um reposicionamento do Governo Federal sobre o tema, valendo-se dos instrumentos disponíveis, dentre os quais a eventual revisão do Parecer AGU/GQ-181 e do Parecer AGU/GQ-22 (Parecer AGU nº LA- 01, de 2010) (...) (Processo Administrativo da AGU nº 00400.000695/2007- 00; Assunto: Aquisição de terras por estrangeiros; Consultor-Geral da União Ronaldo Jorge Araújo Vieira Júnior; Brasília, 03 de setembro de 2008). 
A alteração do entendimento não agradou grande parte da comunidade jurídica, sobretudo em razão da motivação alheia à análise intrinsecamente jurídica da disciplina.

Neste aspecto, os defensores da tese adversa logo reforçaram que a força normativa do parecer não ultrapassava o âmbito da Administração Pública Federal, não vinculando os demais órgãos, entidades e sobretudo, poderes.

Daí decorreu uma celeuma que tem se estendido diante da ausência de provocação do Supremo Tribunal Federal em sede de controle concentrado de constitucionalidade, para manifestar-se sobre o tema.

Ocorre que os serviços extrajudiciais, também denominados de cartórios extrajudiciais, não estão vinculados à Administração Pública Federal pois constituem órgãos integrantes dos Poderes Judiciários estaduais, subordinando-se diretamente às normativas expedidas pelos respectivos Tribunais de Justiça.

Sendo assim, a princípio, os oficiais de registros imóveis poderiam registrar títulos de aquisição de imóveis rurais sem a necessidade de observar o entendimento da Advocacia Geral da União.

O descompasso foi logo constatado, levando o Conselho Nacional de Justiça a se manifestar, após a devida provocação promovida pelo Ministério Público Federal.

O CNJ no exercício de sua função de fiscalização e controle dos atos administrativos do Poder Judiciário e seus serviços agregados, abrangidos os serviços extrajudiciais, se manifestou através do Pedido de Providências $n^{\circ}$ 0002981-80.2010.2.00.0000, expedindo a seguinte recomendação dirigida às Corregedorias estaduais:

Ante o exposto, considerando as razões enunciadas pela Procuradoria da República e levando em conta manifestação do Consultor-Geral devidamente aprovado pelo Advogado-Geral no âmbito da AGU tanto como atento às recomendações do Tribunal de Contas da União, esta Corregedoria Nacional de Justiça em face dos serviço judiciários auxiliares - nomeadamente os serviços notariais e registrais - deve recomendar fortemente a imediata adoção pela Corregedorias locais ou regionais junto aos Tribunais respectivos que determinem aos Cartórios de Registro de Imóveis e Tabelionatos de Notas que façam observar rigorosamente as disposições da Lei $\mathrm{n}^{\circ}$ 5.709, de 1971, quando se apresentarem ou tiverem de lavrar atos de aquisição de terras rurais por empresas brasileiras com participação majoritária de estrangeiros, pessoas físicas ou jurídicas (CNJ; Pedido de Providência $\mathrm{n}^{\text {o }}$ 0002981-80.2010.2.00.0000; Relator Conselheiro Gilson Dipp; julgado em 20.10.2010) 
O debate não se encerra com a decisão expedida pelo Conselho Nacional de Justiça, mesmo com a adesão integral da recomendação pelos Estados, isso porque nada impede que os prejudicados busquem a jurisdição para pleitear a não aplicação do famigerado $\S^{\circ}$ do artigo $1^{\circ}$ da Lei $n^{\circ} 5.709$, de 1971, tendo em vista a ausência de natureza jurisdicional da decisão proferida pelo $\mathrm{CNJ}$.

\section{CONSIDERAÇÕES FINAIS}

O atual posicionamento adotado pela Advocacia-Geral da União a respeito da recepção da norma inculta no $\S^{\circ}$ do artigo $1^{\circ}$ da Lei $n^{\circ} 5.709$, de 1971 , é altamente questionável.

Sobre o viés legal, pesa em desfavor do Parecer LA-01/2010 a discriminação que se promove entre pessoas jurídicas nacionais, sem que haja uma situação fática plausível a justificar o tratamento diferenciado.

Nas palavras de Humberto Ávila, diferenciar sem razão é violar o princípio da igualdade (ÁVILA, 2014, p. 157).

Ademais, fundamentar a discriminação realizada em uma cláusula jurídica aberta, como é o interesse jurídico e o nacional, sem que se demonstre, efetivamente, de que forma a norma resguarda esses postulados, gera enorme indeterminação e subjetividade, o que afronta frontalmente o princípio da segurança jurídica, um dos pilares de nosso ordenamento.

Por outro lado, após uma análise meramente perfunctória pode-se concluir que mesmo aplicado o entendimento exarado no Parecer LA-01/2010, inexiste uma sistemática de controle e fiscalização que permita verificar as alterações de controle acionário das sociedades supervenientes ao registro de aquisição da propriedade rural.

Quer dizer, o Oficial do Registro de Imóveis somente verificará a constituição do capital do social no momento em que realizar a qualificação para registro do título de aquisição (em regra, a escritura pública de venda e compra), inexistindo disposição legal que obrigue a sociedade a comunicar as alterações societários posteriores.

Se o objetivo da norma é propiciar um criterioso controle das áreas rurais sob domínio estrangeiro para evitar a valorização desarrazoada do preço da terra, o crescimento da venda ilegal de terras públicas, a utilização de recursos oriundos da lavagem de dinheiro, o aumento da grilagem de terra e outras situações frisadas pelo Advogado Geral da União em seu parecer, deve (o controle), para ser efetivo, se dar de forma contínua e permanente. Da forma tal qual foi erigida a sistemática de fiscalização, a norma se torna ineficiente em sua determinação. 
Por fim, imprescindível concluir que a matéria merece ser levada a pacificação perante o Supremo Tribunal Federal em sede de controle concentrado de constitucionalidade, órgão jurisdicional competente para tanto. Permitir que uma questão tão relevante seja subjugada ao entendimento sufragado em atos normativos secundários expõe a fragilidade de nosso ordenamento e afronta o tão esquecido princípio da segurança jurídica.

\section{REFERÊNCIAS BIBLIOGRÁFICAS}

ARRUDA, Ridalvo Machado de. Conceitos e Imóvel Rural: Aplicação na Certificação do Incra Expedida no Memorial Descritivo Georreferenciado. Disponível em: http://irib.org.br/arquivos/biblioteca/4108_integra.pdf; Acessado em: 03/08/2015.

ÁVILA, Humberto Bergmann. Teoria dos Princípios: da definição a aplicação dos princípios jurídicos. $7^{a}$ ed. São Paulo: Malheiros, 2014.

CARVALHO, Josué Tomazi de; FIDELES, Junior Divino; MACIEL, Marcela ALBUQUERQUE. Direito Agrário. Salvador: JusPodivm, 2015.

CARVALHO, Kildare Gonçalves. Direito Constitucional: Teoria Geral do Estado e Direito Constitucional Positivo. 14ª ed. Belo Horizonte: Del Rey, 2008.

CYSNEIROS, Vicente Cavalcanti. O Estrangeiro e a Propriedade Rural. Porto Alegre: Sérgio Fabris, 1985.

GUIMARÃES, Francisco Xavier da Silva. Nacionalidade: aquisição, perda e reaquisição. Rio de Janeiro: Forense, 2002.

MALUF, Carlos Alberto Dabus. Limitações ao Direito de Propriedade. $3^{\text {a }}$ ed. São Paulo: RT, 2011.

NUSDEO, Fábio. Curso de Economia: Introdução ao Direito Econômico. $5^{\mathrm{a}}$ ed. São Paulo: Revista dos Tribunais, 2008. 
PELUSO, Cezar (Coord.). Código Civil: doutrina e jurisprudência: Lei n. 10.406, de 10.01.2002. $4^{\mathrm{a}}$ ed. Barueri/SP: Manole, 2010.

SOUZA, Eduardo Pacheco Ribeiro de. Os Imóveis Rurais na Prática Notarial e Registral Noções Elementares. $2^{\text {a }}$ ed. São Paulo: IRIB, 2014.

TARTUCE, Flávio. Manual de Direito Civil: volume único. $3^{\mathrm{a}}$ ed. Rio de Janeiro: Forense; São Paulo: Método, 2013. 